\title{
MANEJO DE LA PUDRICIÓN RADICAL (Phytophthora cinnamomi RANDS) DEL AGUACATE (Persea americana LINNEO)
}

\section{MANAGEMENT OF AVOCADO (Persea americana LINNEO) ROOT ROT (Phytophthora cinnamomi RANDS)}

\author{
José Manuel Leal ${ }^{1}$, Jairo Castaño ${ }^{2}$, Martha M. Bolaños ${ }^{3}$
}

\begin{abstract}
${ }^{1}$ Ingeniero Agrónomo. Candidato a Magister en Fitopatología, Departamento de Producción Agropecuaria, Facultad de Ciencias Agropecuarias, Universidad de Caldas, calle 65 No. 26-10, Manizales, Colombia, e-mail: jose_manuelleal@hotmail. es; ${ }^{2}$ Ph.D. Profesor Titular, Departamento de Producción Agropecuaria, Facultad de Ciencias Agropecuarias, Universidad de Caldas, calle 65 No. 26-10, Manizales, Colombia, e-mail: jairo.castano_z@ucaldas.edu.co; autor para correspondencia. ${ }^{3}$ Ph.D. Corporación Colombiana de Investigación Agropecuaria (CORPOICA). C.I. Tibaitatá, Colombia, e-mail: mmbolanos@ corpoica.org.co
\end{abstract}

Rev. U.D.C.A Act. \& Div. Cient. 17(1): 105-114, Enero-Junio, 2014

\section{RESUMEN}

Para encontrar estrategias nuevas de manejo de la pudrición radical del aguacate, se evaluó el fosfito de potasio, Metalaxil + Mancozeb, Mancozeb + Fosetil-Al, Trichoderma harzianum y una cobertura orgánica a base de bagazo de caña; el estudio, se realizó en CORPOICA, Palmira. Se caracterizaron los aislamientos Ag-037 y Ag-040, como Phytophthora cinnamomi. El experimento comprendió seis tratamientos, en un diseño de bloques completos al azar, con tres repeticiones, en un arreglo de parcelas divididas, con dos tipos de fertilización; la unidad experimental constó de nueve plántulas, variedad Waldin. La inoculación de P. cinnamomi, se realizó 30 días después de la germinación de las semillas, con una concentración de $1 \times 10^{5}$ esporangios $/ \mathrm{mL}$, aplicada al sustrato en tres orificios equidistantes a $5 \mathrm{~cm}$ del tallo, empleando 20 $\mathrm{mL}$ por plántula. Los tratamientos, se efectuaron a partir de las cuatro semanas después de la inoculación, SDI y se realizaron tres aplicaciones cada 30 días. Se evaluó incidencia y severidad de la enfermedad, población de P. cinnamomi, altura de plántulas, peso seco y actividad enzimática de la celulasa. Las evaluaciones, se hicieron a las 6, 12 y 18 SDI. La incidencia de la enfermedad fue del $100 \%$, pero la severidad osciló entre 5 y $22 \%$. Hubo reducción de la severidad de la enfermedad en un 35\%, destacándose Metalaxil + Mancozeb, Mancozeb + Fosetil-Al y Fosfito de potasio, que disminuyeron en $42 \%$ la población de $P$. cinnamomi y en $50 \%$ la severidad, aumentando en $28 \%$ la altura de las plántulas y $66 \%$ el peso seco.

Palabras clave: Straminipila, Trichoderma harzianum, Fosfito, Mancozeb-Metalaxil, Fosetil-Al, actividad enzimática.

\section{SUMMARY}

To find new strategies for the management of avocado root rot, it was evaluated potassium phosphite, Metalaxyl + Mancozeb, Fosetyl-Al + Mancozeb, Trichoderma harzianum and mulch prepared with sugar cane bagasse rich in cellulose. The study was conducted at CORPOICA, Palmira. It was characterized the isolates Ag-037 and Ag-040, as Phytophthora cinnamomi. The experiment consisted of six treatments, in a randomized complete block design with three replications, using a split plot arrangement with two types of fertilization (chemical and integrated), The experimental unit consisted of nine seedlings of the Waldin variety. Seedlings of month old were inoculated with P. cinnamomi at a concentration of $1 \times 10^{5}$ sporangia per $\mathrm{mL}$ and the substrate was performed in three holes at 5 $\mathrm{cm}$ from the root collar y applied $20 \mathrm{~mL}$ of the suspension for seedling. The treatments were applied one month after of inoculation and three applications were made every 30 days. Disease incidence, population of $P$. cinnamomi in the soil, disease severity, seedling height, dry weight and enzyme activity of cellulose were evaluated at 6,12 and 18 weeks after the inoculation. The root rot incidence in avocado seedlings was $100 \%$, but the disease severity, ranged between $5 \%$ and $22 \%$. Overall, the reduction in disease severity was of $35 \%$. The treatments with Metalaxyl + Mancozeb, Fosetyl-Al + Mancozeb and Potassium phosphite reduced in $42 \%$ the population of $P$. cinnamomi in the soil and in $50 \%$ the disease severity, these treatments increased $28 \%$ the height and $66 \%$ the dry weight of the seedlings.

Key words: Straminipila, Trichoderma harzianum, Phosphite, Mancozeb - Metalaxil, Fosetyl-Al, enzymatic activity. 


\section{INTRODUCCIÓN}

La Pudrición de la raíz del aguacate causada por Phytophthora cinnamomi, es la enfermedad más devastadora del aguacate, en el ámbito mundial (Pegg et al. 2002; Bartoli, 2008). Las condiciones del suelo que predisponen a la planta al ataque son la compactación, la poca aireación en suelos pesados y arcillosos y un $\mathrm{pH}$ de 6,5. El riego por aspersión aumenta la incidencia de la enfermedad (Vidales \& Alcántar, 2006). El patógeno es un habitante natural del suelo, que puede sobrevivir hasta por seis años en suelo húmedo, mediante oosporas, clamidosporas o esporangios (Bartoli, 2008).

El manejo de la enfermedad debe ser integrado, combinando productos químicos con podas severas al follaje, adición de materia orgánica al suelo, buen drenaje y mejoramiento genético, mediante, el cual, se ha encontrado resistencia moderada a P. cinnamomi, en las variedades Duke 6, Duke 7 y Thomas, pero estos patrones no se emplean comercialmente en Colombia, siendo la mejor alternativa, a largo plazo (Tamayo, 2008).

Para el control del patógeno, se destacan dos grupos de fungicidas: Acilalaninas o Fenilamidas, específicos para patógenos del Reino Straminipila, suprimen el desarrollo de Phytophthora, actúan sobre la biosíntesis del ADN y tienen alto riesgo de generar resistencia, por esta razón, se recomienda en combinación con fungicidas de amplio espectro, como Mancozeb. Sus ingredientes activos son benalaxil, furalaxil y metalaxil, siendo este último, el más ampliamente utilizado para tratamiento de suelo y de semillas (Agrios, 2005; Mondino, 2008; FRAC, 2011) y Etilenfosfonatos, en el cual, se encuentra Fosetil-Al, muy efectivo contra Phytophthora. Su modo de acción es desconocido (FRAC, 2011), aunque ha sido reportado estimular reacciones de defensa y de síntesis de fitoalexinas en la planta contra Straminipilas (Agrios, 2005). Hay pocos reportes de resistencia, lo que indica, que es de bajo riesgo. Su movimiento bidireccional en la planta lo hace único (Mondino, 2008; FRAC, 2011).

Las sales de fosfito, el calcio y el fosfito de magnesio pueden ser utilizadas como fungicidas biodegradables, para proteger las plantas. El fosfito estimula las defensas naturales de la planta permitiendo sobrevivir a las ya infectadas. El fósforo (P) es vital para el crecimiento radical. Los niveles de $\mathrm{P}$ adecuados garantizan un sistema radical sano (Bernal \& Ballen, 2007).

Microorganismos antagónicos. Los patógenos habitantes del suelo pueden ser invadidos y parasitados por varios hongos. Los más comunes son Trichoderma harzianum y algunas especies de Straminipilas, del género Pythium, que inhiben el crecimiento o parasitan especies de Phytophtho- ra. Bacterias de los géneros Bacillus, Enterobacter, Pseudomonas y Pantoea, también lo hacen (Agrios, 2005).

En este estudio, se evaluó, en condiciones de vivero, el efecto de tres fungicidas: Fosfito de potasio (Foscrop ${ }^{\circledR} \mathrm{PK}$ ), Metalaxil + Mancozeb (Ridomil Gold ${ }^{\circledR}$ MZ 68 WP) y Mancozeb + Fosetil-Al (Rhodax 70 WP); un producto biológico: Trichoderma harzianum (Protector ${ }^{\circledR} \mathrm{WP}$ ) y una enmienda orgánica (cobertura orgánica), a base de bagazo de caña, rico en celulosa (46\%).

\section{MATERIALES Y MÉTODOS}

El estudio, se realizó en el Centro de Investigación Palmira (C.I. Palmira) de CORPOICA. En el laboratorio de fitopatología, se llevaron a cabo los aislamientos de $P$. cinnamomi, de muestras de raíces de árboles de aguacate, que presentaron síntomas de la Pudrición radical.

Se efectuó la siembra en cajas Petri, con medio selectivo PDA + antibióticos + fungicidas [PDA (39g/L), Ampicilina $(250 \mu \mathrm{g} / \mathrm{mL})$, Rifampicina $(10 \mu \mathrm{g} / \mathrm{mL})$, Penicilina $(400 \mu \mathrm{g} /$ $\mathrm{mL})$, Benomil $(20 \mu \mathrm{g} / \mathrm{mL})$, PCNB $(200 \mu \mathrm{g} / \mathrm{mL})$ e Hymexazol $(25 \mu \mathrm{g} / \mathrm{mL})]$ (Tsao \& Guy, 1983); las muestras, se incubaron a $27,7^{\circ} \mathrm{C}$, en una incubadora, a los dos días se observaron las siembras y, a las que mostraron crecimiento micelial, se les realizó nuevas siembras para su purificación. Se obtuvieron cuatro aislamientos, que fueron identificados morfológicamente, con las claves dicotómicas, descritas por Ho (1992) y Ho et al. (1995) y, molecularmente, mediante la técnica PCR y PCR-RFLP, en la que se amplificaron fragmentos de ADN ribosomal, por medio de la técnica de Reacción en Cadena de la Polimerasa (PCR) y se analizó el tamaño de los fragmentos amplificados, por electroforesis. Para esto, se empleó el cebador A2 (ACTTTCCACGTGAACCGTTTCAA) en combinación con el cebador I2 (GATATCAGGTCCAATTGAGATGC) (Drenth et al. 2006). Para la reacción de PCR, se

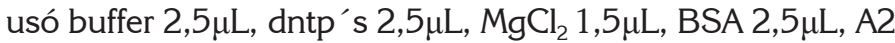
$0,25 \mu \mathrm{L}$, I2 $0,25 \mu \mathrm{L}$, taq $0,2 \mu \mathrm{L}$, agua $13,8 \mu \mathrm{L}$ para un volumen final de $23,5 \mu \mathrm{L}$. La amplificación del ADN con los cebadores A2/I2, se procedió en un termociclador PTC-100, utilizando un perfil, que consistió en la desnaturalización inicial a $94^{\circ} \mathrm{C}$ por $5 \mathrm{~min}, 94^{\circ} \mathrm{C}$ por $30 \mathrm{~s}, 60^{\circ} \mathrm{C}$ por $30 \mathrm{~s}, 72^{\circ} \mathrm{C}$ por $1 \mathrm{~min}$, seguido de 25 ciclos de amplificación desde el paso $2,72^{\circ} \mathrm{C}$ por $10 \mathrm{~min}$ y $15^{\circ} \mathrm{C}$ por $30 \mathrm{~min}$. La visualización del producto, se realizó en un gel de agarosa al 3\%, teñido con bromuro de etidio $(0,1 \mathrm{ppm})$, a 100 voltios durante $2 \mathrm{~h}$. Para la identificación de la especie, se cortaron con enzimas de restricción MspI, Rsal, los fragmentos del tamaño esperado, con los cebadores A2/I2, usando las condiciones descritas por Drenth et al. (2006).

La fase de campo, se hizo en una casa de malla del mismo centro de investigación, donde se evaluó el efecto de los 
fungicidas Fosfito de potasio, Metalaxil $4 \%+$ Mancozeb 64 $\%$, Fosetil-Al 35\% + Mancozeb 35\%, un producto biológico a base de Trichoderma harzianum y una enmienda orgánica (cobertura orgánica) a base de bagazo de caña, con alto contenido de celulosa (46\%), en plántulas de aguacate, variedad Waldin, inoculadas con P. cinnamomi, a partir de un mes de edad. Se emplearon seis tratamientos, incluyendo al testigo: T0 = Plántulas Testigo inoculadas con P. cinnamomi; T1 = Fosfito de potasio [P2O5 420g/L + K2O 280g/L (Foscrop $\left.\left.{ }^{\circledR} \mathrm{PK}\right)\right]$, en dosis de $10 \mathrm{~mL}$ de p.c. /L de agua; T2 = Fosetil-Al 35\% + Mancozeb 35\% (Rhodax ${ }^{\circledR} 70$ WP), en dosis de $5 \mathrm{~g}$ de p.c. $/ \mathrm{L}$ de agua; T3 = Metalaxil $4 \%+$ Mancozeb 64 \% (Ridomil Gold $₫$ MZ 68 WP), en dosis de 3,75g de p.c. /L de agua; T4 = Enmienda orgánica a base de bagazo de caña picado, en dosis de $2 \mathrm{~kg} /$ planta, inoculado con Trichoderma harzianum a 2 x 105 UFC viables/g de producto (Protector ${ }^{\circledR}$ WP), en dosis de $1 \mathrm{~g}$ de p.c./L de agua y T5 = Trichoderma harzianum: 2 x 105 UFC viables/g de producto (Protector ${ }^{\circledR}$ $\mathrm{WP})$, en dosis de $1 \mathrm{~g}$ de p.c./L de agua.

Estos tratamientos fueron evaluados bajo dos tipos de fertilización: $F_{1}=$ Fertilización química: realizada según los resultados del análisis de suelo y $F_{2}=$ Fertilización integrada: consistente en la aplicación de fertilizantes orgánicos, químicos y biofertilizantes. Se empleó abono orgánico a base de gallinaza (Aviabono ${ }^{\circledR}$ ), en dosis de $200 \mathrm{~g} /$ plántula y los biofertilizantes: Dimazos ${ }^{\circledR}$ (fijadores de nitrógeno), a base de Azotobacter chroococcum $1 \times 10^{6} \mathrm{UFC} / \mathrm{mL}$ y Azospirillum sp. $1 \times 10^{6} \mathrm{UFC} / \mathrm{mL}$, en dosis de $200 \mathrm{~mL}$ p.c./L de agua, aplicando $100 \mathrm{~mL}$ de la solución por plántula y Fosfosol ${ }^{\circledast}$ (solubilizador de fósforo), a base de Penicillium janthinellum $1 \times 10^{7}$ conidios/mL, en dosis de $10 \mathrm{~mL}$ p.c./L de agua, aplicando $200 \mathrm{~mL}$ de la solución por plántula.

Se empleó un diseño de bloques completos al azar, con tres repeticiones, en un arreglo de parcelas divididas (Little \& Hills, 1987). Se utilizaron nueve plántulas de aguacate de un mes de edad por tratamiento, como unidad experimental; el tamaño de la muestra empleada en cada evaluación fue de tres plántulas por tratamiento.

Se usó semilla de la variedad Waldin, que se desinfectó en una solución de Carboxin (Vitavax ${ }^{\circledR}$ ) (2g de p.c./L) y Clorpirifos (Lorsban $^{\circledR}$ ) (2mL de p.c./L) (Tamayo, 2008). Las semillas, se sembraron en bolsas de polietileno negras, calibre 3; el suelo se desinfestó con Dazomet (Basamid $\left.{ }^{\circledR} \mathrm{GR}\right)\left(50 \mathrm{~g}\right.$ de p.c. $/ \mathrm{m}^{2} \mathrm{de}$ suelo), luego se humedeció y se cubrió con plástico negro durante 15 días; posteriormente, se destapó, se revolvió el suelo y se dejó airear por otros 15 días (Tamayo, 2008).

Para la inoculación de $P$. cinnamomi, se utilizaron las cepas Ag-037 y Ag-040; la inoculación, se realizó a los 30 días después de la germinación de las semillas; la suspensión de $P$. cinnamomi, se preparó a una concentración de $1 \times 10^{5}$ es-
porangios/mL (Latorre, 1988). La inoculación, se efectuó al sustrato en tres orificios equidistantes a $5 \mathrm{~cm}$ del cuello de la raíz principal y se aplicaron $20 \mathrm{~mL}$ de la suspensión por plántula; luego, se aplicó riego diario, para proveer las condiciones favorables para el desarrollo del patógeno.

Los tratamientos químicos y biológicos, se iniciaron un mes después de la inoculación; se aplicaron $200 \mathrm{~mL}$ de la solución de cada producto al suelo, saturando la zona radical de cada plántula de aguacate; se realizaron tres aplicaciones cada 30 días.

Para el análisis de varianza, se manejó el programa Statistical Analysis System, SAS, complementado con la prueba de comparación de medias de Tukey al 5\%.

Variables de respuesta: Se hicieron evaluaciones a las 6, 12 y 18 semanas después de la inoculación, a las variables de respuesta: porcentaje de incidencia, población de $P$. cinnamomi en el suelo, severidad, altura de plántulas y peso seco de las plántulas; también, se hizo análisis foliar de nutrimentos y de actividad enzimática de la celulasa en suelo, a las 18 semanas. Incidencia (\%): el porcentaje de plantas afectadas por la pudrición radical, se calculó relacionando el número de plántulas afectadas con el número total de plántulas de aguacate de cada tratamiento. Población del patógeno en la rizósfera: se tomaron tres muestras de suelo entre 10 y $20 \mathrm{~cm}$ de profundidad en la zona radical (rizósfera) de cada plántula, el equivalente de $10 \mathrm{~g}$ de suelo (peso seco), se mezcló con $100 \mathrm{~mL}$ de una solución agua-agar al $0,25 \%$; luego, se tomaron $2 \mathrm{~mL}$ de la suspensión (suelo-agua-agar), se sembraron en cajas Petri con medio selectivo (PDA+ antibióticos + fungicidas), para P. cinnamomi (Kellan \& Coffey, 1985); posteriormente, se incubaron a $27,7^{\circ} \mathrm{C}$, por tres días, después se realizó el conteo del número de colonias presentes en cada caja Petri, expresado en propágulos por gramo de suelo seco (Gabor \& Coffey, 1990). Severidad (\%): las plántulas de aguacate de cada tratamiento y de los tipos de fertilización, se separaron de la bolsas y se retiró la tierra de las raíces, se procedió a un lavado completo del sistema radical y, la evaluación, se practicó visualmente en cada una de las plántulas, utilizando la escala descriptiva, propuesta por Castaño-Zapata (1989), en donde: 1 = Plantas sanas o base del tallo sano, hasta el $1 \%$ de las raíces afectadas; $3=$ Base del tallo ligeramente necrosado, alrededor del $5 \%$ de las raíces afectadas; 5 = Base del tallo necrosado, alrededor del $10 \%$ de las raíces afectadas; $7=$ El tercio inferior del tallo necrosado, alrededor del $25 \%$ de las raíces afectadas, observándose, además, una marcada reducción del sistema radical y 9 = Tallo totalmente necrosado, alrededor del $50 \%$ o más de las raíces afectadas, ocasionando una reducción severa en el número y longitud de las raíces. Análisis foliar de nutrimentos: se recolectaron cuatro hojas expandidas de cada plántula de aguacate, se empacaron en bolsas de papel 
y se marcaron; luego, se colocaron en un horno de secado a $70^{\circ} \mathrm{C}$ por tres días; posteriormente, se pesaron $30 \mathrm{~g}$ de hojas secas por tratamiento y de cada tipo de fertilización y se enviaron al laboratorio de Química de Suelos del C.I. Tibaitatá (CORPOICA), Bogotá, para su respectivo análisis. La interpretación de los resultados del análisis foliar de macro y de micronutrientes, se realizó siguiendo el criterio de Chapman (1973). Altura (cm) de plántulas: se utilizaron tres plántulas por tratamiento y en cada tipo de fertilización, se tomó desde la base de la plántula (cuello de la raíz principal) hasta la hoja recién emitida y expandida. Peso seco $(\mathrm{g})$ de raíces, tallo y hojas: las muestras se dispusieron dentro de bolsas de papel, se rotularon y se colocaron dentro de un horno de secado a $75^{\circ} \mathrm{C}$ por tres días; posteriormente, se sacaron y se pesaron en una balanza analítica. Actividad enzimática de la celulasa en el suelo rizosférico: se tomaron tres submuestras de suelo de la rizósfera de cada plántula, entre 5 y $10 \mathrm{~cm}$ de profundidad; estas submuestras se mezclaron para obtener una sola muestra por cada tratamiento; las muestras fueron empacadas en bolsas plásticas y rotuladas, se colocaron en una caba de icopor con hielo y se enviaron a CORPOICA; el procesamiento, se efectuó según el método de Pancholy \& Rice (1973), modificado por García-Álvarez \& Ibáñez (1994).

\section{RESULTADOS Y DISCUSIÓN}

Caracterización molecular de Phytophthora cinnamomi mediante PCR-RFLP: los aislamientos fueron analizados por la técnica de PCR-RFLP, mediante la amplificación de la región ITS, con los cebadores específicos A2/I2, utilizados para la detección de especies de Phytophthora; en los aislamientos Ag-040 y Ag-037, se obtuvo una banda de 828 pb, identificando estos aislamientos dentro del género Phytophthora (Figura 1); las bandas obtenidas de los diferentes aislamientos con los cebadores A2/I2 fueron digeridas con dos enzimas de restricción MspI, Rsal (Figura 2), obteniendo la igualdad en el tamaño de bandas de $123 \mathrm{pb}$ para la especie Phytophthora cinnamomi (Drenth et al. 2006).

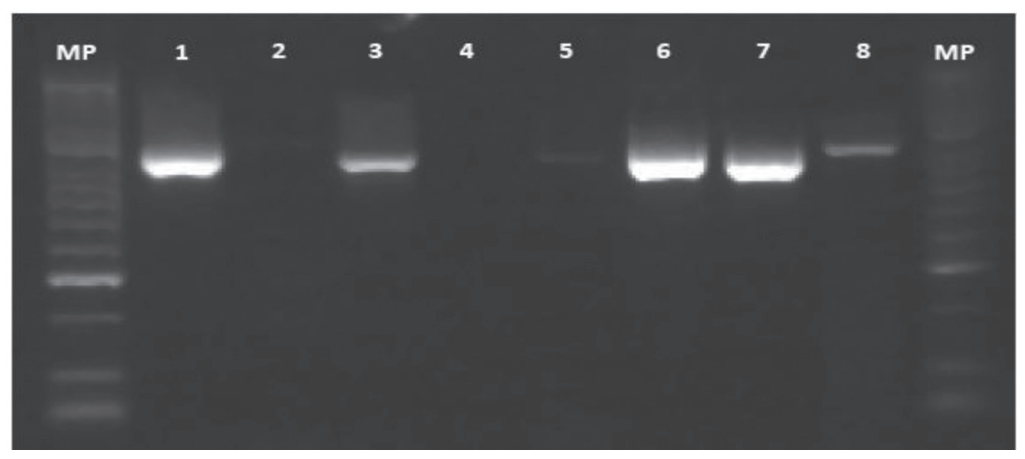

Figura 1. Cebadores específicos A2/l2. 1) Aislamiento Ag-040; 2) Aislamiento Ag-041; 3) Aislamiento de Phytophthora spp. UNAL Palmira; 4) Control negativo; 5) Aislamiento Ag-034; 6) Aislamiento Ag-037; 7) Control positivo Phytophthora palmivora y 8) Control positivo Phytophthora cinnamomi.

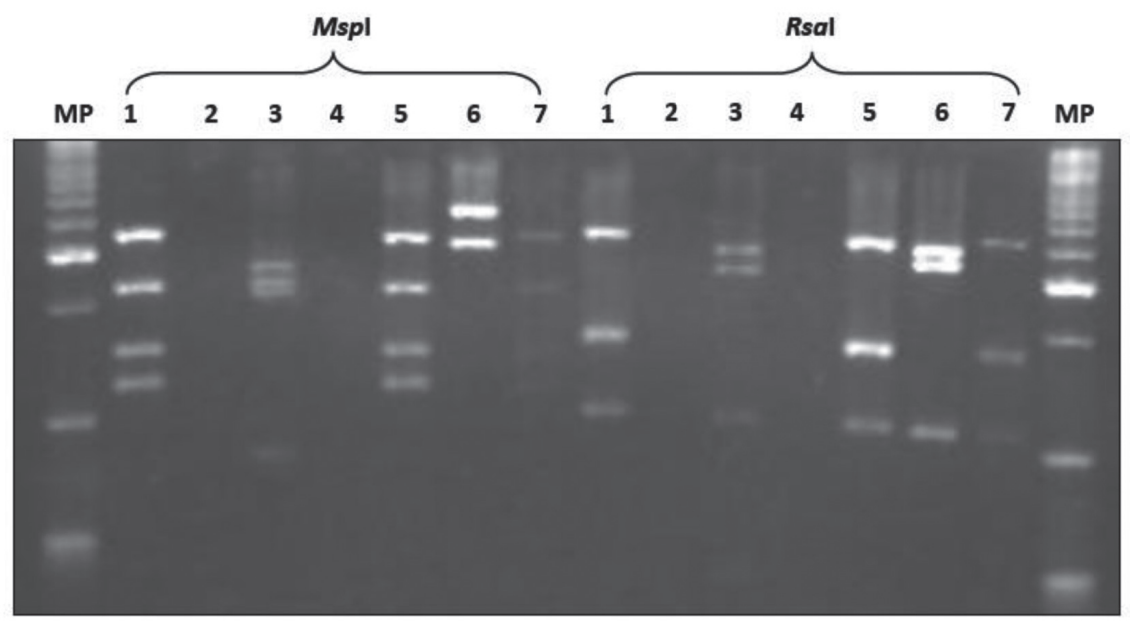

Figura 2. Digestión del producto amplificado A2/I2, con las enzimas de restricción Mspl, Rsal. 1) Aislamiento Ag-040; 2) Aislamiento Ag-041; 3) Phytophthora spp.; 4) Aislamiento Ag-034; 5) Aislamiento Ag-037; 6) Phytophthora palmivora y 7) Phytophthora cinnamomi. 
Incidencia (\%) de la enfermedad: el $100 \%$ de las plántulas fueron afectadas por la enfermedad, algunas presentaron síntomas de marchitez hasta llegar a la muerte, demostrando que los aislamientos Ag-037 y Ag-040 de P. cinnamomi fueron efectivos en producir la infección de las raíces.

Propágulos del patógeno en la rizósfera (pgs): hubo diferencias significativas entre tratamientos. En los tratamientos químicos y en las tres evaluaciones con Mancozeb $64 \%+$ Metalaxil $4 \%$, Mancozeb 35\% + Fosetil-Al 35\% y el Fosfito de potasio, hubo una disminución en la población del patógeno en el suelo, de 41,30 y $48 \%$, respectivamente, en relación a las plántulas testigo (Tabla 1); en los tratamientos con bagazo de caña $+T$. harzianum y $T$. harzianum, se observó la colonización de T. harzianum sobre P. cinnamomi (Figura 3); coincidiendo con los resultados de García et al. (2003), quienes indican que Trichoderma es un microorganismo celulolítico y los de Erwin \& Ribeiro (1996), quienes demostraron que T. harzianum es un hongo inhibitorio de P. cinnamomi, vía competición, antibiosis o parasitismo.

Los promedios entre tratamientos en los tres períodos evaluados presentaron una disminución en la población del patógeno en el suelo, del 12, 13 y 5\% en la fertilización inte- grada, destacándose el tratamiento con Mancozeb $64 \%+$ Metalaxil 4\%, con relación a la fertilización química; el suelo utilizado en el experimento tuvo un $\mathrm{pH}$ por encima de 6 y el contenido de materia orgánica fue superior a $7 \%$; además, en la fertilización integrada, se aplicó materia orgánica a base de gallinaza, concordando con Pegg et al. (1982) y Broadbent \& Baker (1974), quienes encontraron que, en suelos con altos niveles de materia orgánica $(>7 \%)$, alta relación C:N y pH superior a 6 , se mantiene una población alta de microorganismos antagónicos, las cuales, pueden reducir la población de $P$. cinnamomi.

Severidad (\%) de la enfermedad: se observó diferencias altamente significativas entre tratamientos en las tres evaluaciones. La prueba de comparación de medias de Tukey al 5\%, mostró al grupo de tratamientos químicos Mancozeb $64 \%+$ Metalaxil 4\%, Mancozeb 35\% + Fosetil-Al 35\% y el Fosfito de potasio, con valores de severidad de la enfermedad más bajos, encontrándose una disminución de 46, 45 y $63 \%$, respectivamente; de igual forma, los tratamientos con bagazo de caña $+T$. harzianum y T. harzianum, presentaron disminución en la severidad, de 19, 28 y 17\%, respectivamente, con respecto al testigo (Tabla 2). También, se observó una disminución en los grados de severidad en el

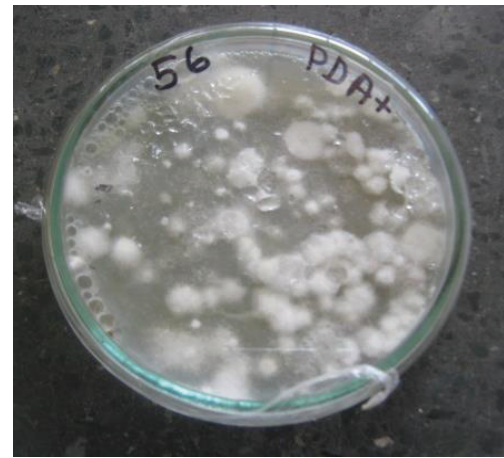

Testigo

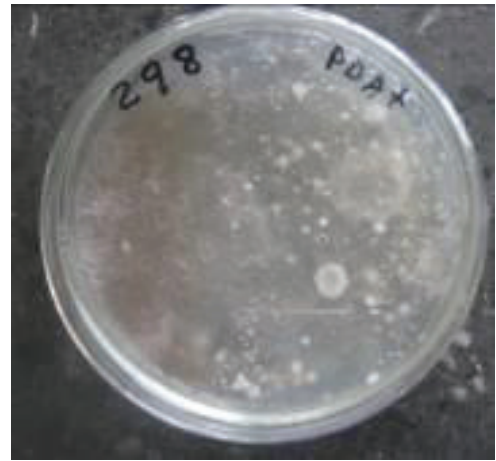

Mancozeb 64\% + Metalaxil 4\%

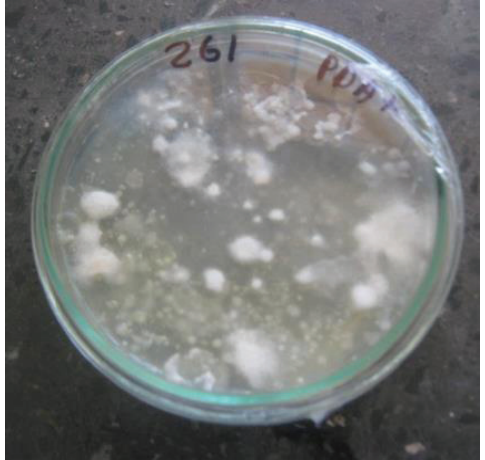

Fosfito de Potasio

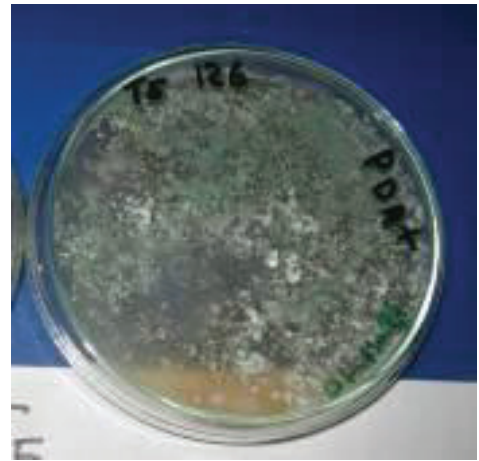

Bagazo de caña $+T$. harzianum

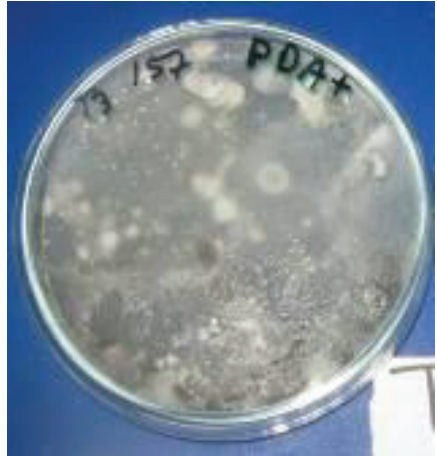

Mancozeb 35\% + Fosetil-Al 35\%

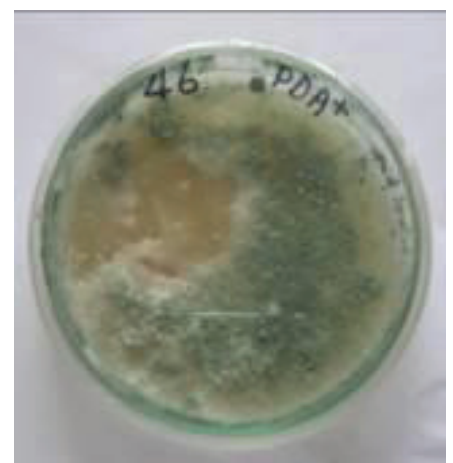

Trichoderma harzianum

Figura 3. Colonias de P. cinnamomi aisladas del suelo, de acuerdo con los tratamientos. 
Tabla 1. Efecto de los productos químicos y biológicos sobre el patógeno en el suelo, después de 6, 12 y 18 semanas de la inoculación de P. cinnamomi.

\begin{tabular}{|c|c|c|c|c|}
\hline \multirow{3}{*}{ Tratamientos } & \multirow{3}{*}{ Dosis } & \multicolumn{3}{|c|}{ Propágulos por gramo de suelo } \\
\hline & & \multicolumn{3}{|c|}{ Semanas } \\
\hline & & 6 & 12 & 18 \\
\hline Mancozeb $64 \%+$ Metalaxil $4 \%$ & $3,7 \mathrm{~g} / \mathrm{L}$ & $20,8 \mathrm{~B} *$ & $26,1 \mathrm{~B}$ & $25,6 \mathrm{C}$ \\
\hline Mancozeb 35\% + fosetil-Al 35\% & $5 \mathrm{~g} / \mathrm{L}$ & 20,8 B & $35,7 \mathrm{AB}$ & $25,9 \mathrm{C}$ \\
\hline Fosfito de potasio & $10 \mathrm{~cm}^{3} / \mathrm{L}$ & $24,9 \mathrm{~B}$ & $32,3 \mathrm{AB}$ & $30,9 \mathrm{BC}$ \\
\hline Bagazo de caña $+T$. harzianum & $2 \mathrm{~kg}$ & $26 \mathrm{AB}$ & $50,3 \mathrm{~A}$ & $37,7 \mathrm{ABC}$ \\
\hline Trichoderma harzianum & $1 \mathrm{~g} / \mathrm{L}$ & $24,1 \mathrm{~B}$ & $36 \mathrm{AB}$ & $38,6 \mathrm{AB}$ \\
\hline Testigo & --- & $35,2 \mathrm{~A}$ & $51,2 \mathrm{~A}$ & $49,9 \mathrm{~A}$ \\
\hline DMS & & 9,5 & 19,1 & 12,3 \\
\hline
\end{tabular}

* Promedios en cada columna con la misma letra no son estadísticamente diferentes, según la prueba de Tukey al $5 \%$.

tipo de fertilización integrada en los tres períodos evaluados, con un porcentaje de disminución de 9,19 y $11 \%$, respectivamente, respuesta que puede ser debida a los ingredientes activos de metalaxil y fosetil-Al, muy activos contra $P$. cinnamomi (Coffey, 1987) y al antagonismo sobre el patógeno de los microorganismos presentes en la materia orgánica. La disminución de la severidad de la Pudrición radical por el efecto de los productos químicos y biológicos, concuerda con Mora et al. (1987), Rosas et al. (1986), Coffey (1987), Valenzuela et al. (1985), Downer et al. (2002), Broadbent \& Baker (1974) y Allen et al. (1980), quienes observaron que algunos de los productos usados, exitosamente, para el manejo de esta enfermedad fueron: Metalaxil, Fosetil-Al, Fosfito de potasio, estiércol de bovino, paja de alfalfa, coberturas orgánicas a base de celulosa, materia orgánica y microorganismos antagonistas.
Altura $(\mathrm{cm})$ de las plántulas de aguacate: se presentaron diferencias altamente significativas y significativas entre tratamientos. En la prueba de comparación de medias de Tukey al $5 \%$, se observó que los tratamientos, en las tres evaluaciones, con químicos (Mancozeb 64\% + Metalaxil 4\%, Mancozeb 35\% + Fosetil-Al 35\% y el Fosfito de potasio), aumentaron la altura de las plántulas; el incremento alcanzó 36,17 y $32 \%$, respectivamente; asimismo, estos tratamientos disminuyeron notablemente la población del patógeno en el suelo y la severidad. Al considerar los tratamientos con bagazo de caña $+T$. harzianum y $T$. harzianum, también presentaron, en la primera y tercera evaluación, un ligero aumento en la altura de las plántulas con respecto al testigo, de 10 y $18 \%$, respectivamente. Los promedios entre tratamientos presentaron un ligero aumento en la altura de las plántulas con la fertilización integrada, siendo de 1,8 y $1,4 \%$,

Tabla 2. Efecto de los productos químicos y biológicos sobre la severidad de la Pudrición radical del aguacate a las 6,12 y 18 semanas después de la inoculación de P. cinnamomi.

\begin{tabular}{|c|c|c|c|c|}
\hline \multirow{2}{*}{ Tratamientos } & \multirow{2}{*}{} & \multirow{3}{|c|}{ Severidad (\%) } \\
\cline { 3 - 5 } & \multirow{2}{*}{ Dosis } & \multicolumn{3}{|c|}{ Semanas } \\
\cline { 3 - 5 } & & 6 & 12 & 18 \\
\hline Mancozeb 64\% + Metalaxil 4\% & $3,7 \mathrm{~g} / \mathrm{L}$ & $3,1 \mathrm{D} *$ & $2,9 \mathrm{C}$ & $2,8 \mathrm{~B}$ \\
\hline Mancozeb 35\% + Fosetil-Al 35\% & $5 \mathrm{~g} / \mathrm{L}$ & $3,3 \mathrm{CD}$ & $3,3 \mathrm{BC}$ & $3,8 \mathrm{~B}$ \\
\hline Fosfito de potasio & $10 \mathrm{~cm}^{3} / \mathrm{L}$ & $4,0 \mathrm{BCD}$ & $2,9 \mathrm{C}$ & $3,1 \mathrm{~B}$ \\
\hline Bagazo de caña + T. harzianum & $2 \mathrm{~kg}$ & $4,7 \mathrm{ABC}$ & $4,7 \mathrm{AB}$ & $6,5 \mathrm{~A}$ \\
\hline Trichoderma harzianum & $1 \mathrm{~g} / \mathrm{L}$ & $5,0 \mathrm{AB}$ & $3,8 \mathrm{ABC}$ & $6,3 \mathrm{~A}$ \\
\hline Testigo & --- & $5,8 \mathrm{~A}$ & $5,3 \mathrm{~A}$ & $7,6 \mathrm{~A}$ \\
\hline DMS & & 1,5 & 1,5 & 2,1 \\
\hline
\end{tabular}

* Promedios en cada columna con la misma letra no son estadísticamente diferentes, según la prueba de Tukey al $5 \%$. 
incremento reflejado en los tratamientos, donde se utilizó Fosfito de potasio y Mancozeb 35\% + Fosetil-Al 35\%.

Peso seco ( $\mathrm{g}$ ) de las plántulas: hubo diferencias significativas y altamente significativas entre tratamientos en la primera y tercera evaluación. La prueba de comparación de medias de Tukey al 5\%, mostró, que en las tres evaluaciones, los tratamientos químicos (Mancozeb 64\% + Metalaxil 4\%, Mancozeb 35\% + Fosetil-Al 35\% y el Fosfito de potasio) produjeron los valores más altos de peso seco de las plántulas, con respecto al testigo; sin embargo, es importante destacar el tratamiento con Mancozeb 35\% + Fosetil-Al 35\%, el cual, presentó en los tres períodos evaluados, los mayores valores de peso seco, con incrementos de 69, 41 y 90\%, respectivamente, con relación al testigo. Tanto el Fosetil-Al y el Fosfito de potasio tienen ingredientes activos similares, que son recomendados como fungicidas y otros como fertilizantes, aunque los fosfitos de potasio son útiles para el control de patógenos (PLM, 2012), también proporcionan resistencia a la enfermedad y un mayor desarrollo de las plántulas de aguacate; de igual forma, las plantas que recibieron los tratamientos con bagazo de caña $+T$. harzianum y T. harzianum, también presentaron un incremento del $19,6 \%$ de peso seco, con relación al testigo.

El promedio de peso seco de las plántulas entre tratamientos conservaron un aumento con la fertilización integrada, siendo los incrementos de 10, 10 y 5\%, destacándose Mancozeb $35 \%$ + Fosetil-AL 35\% y Fosfito de potasio; concluyendo que la acción de la materia orgánica y los biofertilizantes utilizados favorecieron el desarrollo de las plántulas de aguacate.

Actividad enzimática de la celulasa ( $\mu$ g de glucosa $\mathrm{g}^{-1}$ suelo seco $\mathrm{h}^{-1}$ ): hubo diferencias altamente significativas entre tratamientos. Los mayores valores de actividad enzimática de la celulasa, se observó en el suelo tratado con bagazo de caña $+T$. harzianum y $T$. harzianum solo, con valores de 0,55 y $0,48 \mu \mathrm{g}$ de glucosa $\mathrm{g}^{-1}$ suelo seco $\mathrm{h}^{-1}$, superiores al del testigo, que fue de 0,45; los tratamientos con Mancozeb 64\% + Metalaxil 4\%, Mancozeb 35\% + Fosetil-Al 35\% y Fosfito de potasio, tuvieron valores de 0,39, 0,37 y 0,24; valores muy por debajo del testigo, que fue de $0,45 \mu \mathrm{g}$ de glucosa $\mathrm{g}$ ${ }^{-1}$ suelo seco $\mathrm{h}^{-1}$; probablemente, los microorganismos del suelo que degradan la celulosa fueron afectados por los fungicidas. El aumento significativo en la actividad enzimática de la celulosa, concuerda con García et al. (2003), quienes encontraron que la celulasa tiene su origen en la acción de los microorganismos celulolíticos, con especies de hongos de Trichoderma, Aspergillus y Penicillium, y bacterias aerobias como anaerobias, como Cytophaga, Cellulomonas, Clostridium y Streptomyces.

El efecto del bagazo de caña $+T$. harzianum y $T$. harzianum, sobre la población de $P$. cinnamomi en el suelo y la severidad de la enfermedad, demuestra que la acción de la celulasa en el desdoblamiento de la celulosa tuvo un efecto adverso sobre $P$. cinnamomi, porque su pared celular, a diferencia de la mayoría de hongos, está compuesta de celulosa y glucanos. En la fertilización integrada hubo un aumento en el sustrato orgánico, que conduce a incrementar la población de hongos y de bacterias en el suelo; este incremento en la biomasa microbiana ha sido asociado con la supresión de la enfermedad (Shea \& Broadbent, 1983; Erwin \& Ribeiro, 1996).

Análisis foliar de macronutrientes: el contenido de materia orgánica, nitrógeno $(\mathrm{N})$, fósforo $(\mathrm{P})$, potasio $(\mathrm{K})$, calcio $(\mathrm{Ca})$, magnesio (Mg) y azufre (S) en el suelo (sustrato) fue alto; sin embargo, la concentración del nitrógeno $(\mathrm{N})$ en las hojas de las plántulas de aguacate, mostraron un nivel deficiente $(<1,6 \%)$ en todos los tratamientos y en los tipos de fertilización; el nivel bajo de $\mathrm{N}$ en las hojas, puede ser debido a la pérdida en el suelo por lixiviación o lavado causado por el agua de riego (Guerrero, 1995) y al ataque severo de $P$. cinnamomi en las raíces de las plántulas de aguacate. El nivel de $\mathrm{P}$ en el tejido foliar fue adecuado $(0,08-0,25 \%)$ en todos los tratamientos, cuya función principal en el suelo es estimular el desarrollo de las raíces; las zoosporas de $P$. cinnamomi infectan, principalmente, a las raíces jóvenes (Castaño-Zapata \& Del Río, 1994) y la diseminación rápida del patógeno, se debe a que las zoosporas son atraídas por sustancias que exudan las raíces (Aveling \& Rijkenberg, 1986; Bekey, 1987; Coffey, 1991).

La concentración de $\mathrm{K}$ en las hojas solamente sobrepasó el nivel deficiente $(>0,35 \%)$, que fue muy similar en todos los tratamientos y en los dos tipos de fertilización; sin embargo, es importante considerar que en el suelo había buena disponibilidad de este elemento, pero no fue absorbido por las plántulas de aguacate en las cantidades necesarias, el elemento es altamente móvil en la planta y puede mejorar la resistencia al ataque de plagas y enfermedades (Tamayo, 2008; Silva, 1994).

El Ca en las hojas solamente sobrepasó el nivel deficiente $(>0,50 \%)$ en todos los tratamientos y en los tipos de fertilización; la absorción del Ca por las plántulas de aguacate fue muy poca; en el suelo había disponibilidad. Según Lee \& Zentmyer (1982), la incorporación de calcio al suelo es importante, ya que se ha demostrado que este elemento reduce la severidad de la Pudrición de la raíz causada por $P$. cinnamomi. El Ca es un ion importante en la estructura de la pared celular, particularmente, de la lamela media y ayuda a el endurecimiento de la pared celular (Silva, 1994).

Análisis foliar de micronutrientes: los resultados del análisis del suelo mostraron concentración alta en hierro (Fe), cobre $(\mathrm{Cu})$ y zinc $(\mathrm{Zn})$ y media de manganeso $(\mathrm{Mn})$ y boro $(\mathrm{B})$; sin embargo, el análisis de tejido foliar en las plántulas de 
aguacate presentaron niveles de concentración deficiente: Cu (<5ppm), Zn (<30 ppm) y B (<50ppm), con excepción del $\mathrm{Fe}$, que presentó un nivel excesivo (>200ppm) y Mn que tuvo un nivel de concentración adecuado (30-200ppm). Los análisis de tejido foliar mostraron poca variación en la concentración de los micronutrientes, entre tratamientos; no obstante, hubo diferencias entre los tipos de fertilización. Por su parte, la Pudrición de las raíces, se desarrolló desde el momento de la inoculación, disminuyendo la posibilidad de absorción y la movilización de los micronutrientes del suelo hacia la parte aérea de las plántulas, mostrando escaso desarrollo foliar y proliferación de raíces nuevas; según Valenzuela et al. (1985), suelos fértiles y con alto contenido de materia orgánica favorecen el crecimiento radical del aguacate, lo cual, permite una remoción rápida de agua y de nutrimentos.

Se concluye que los aislamientos Ag-037 y Ag-040 caracterizados morfológica y molecularmente, como Phytophthora cinnamomi, causaron incidencia del $100 \%$ de la Pudrición radical. La fertilización química y biofertilización disminuyeron la población de $P$. cinnamomi en el suelo y la severidad de la enfermedad; de igual forma, aumentaron la altura y el peso seco de las plántulas de aguacate. En la fertilización integrada hubo una disminución significativa en la población de $P$. cinnamomi en el suelo y la severidad de la enfermedad, con relación a la fertilización química; asimismo, mostró un aumento en la altura de las plántulas y el peso seco, en las primeras evaluaciones.

Los suelos tratados con bagazo de caña $+T$. harzianum y T. harzianum solo, presentaron los valores más altos de actividad enzimática de la celulasa, respecto al testigo; es importante considerar que el bagazo tiene un contenido alto de celulosa (46\%) y T. harzianum es un microorganismo celulolítico que, al degradarse la celulosa, puede tener un efecto adverso contra $P$. cinnamomi, cuya pared celular está compuesta de celulosa y glucanos.

Mancozeb $64 \%$ + Metalaxil 4\%, Mancozeb 35\% + Fosetil-Al $35 \%$, Fosfito de potasio, T. harzianum y cobertura orgánica a base de bagazo de caña con alto contenido de celulosa y suelos fértiles con alto contenido de materia orgánica, disminuyeron significativamente la enfermedad, indicando que pueden ser utilizados en programas de manejo integrado de la enfermedad.

Agradecimientos. A CORPOICA, Centro de Investigación Palmira, por el apoyo financiero. Al CIAT, por la identificación molecular de $P$. cinnamomi mediante PCR y PCR-RFLP. Conflicto de intereses: El manuscrito fue preparado y revisado con la participación de todos los autores, quienes declaramos que no existe ningún conflicto de intereses que ponga en riesgo la validez de los resultados presentados. Financiación: Este estudio fue financiado por la Corporación Colombiana de Investigación Agropecuaria.

\section{BIBLIOGRAFÍA}

1. AGRIOS, G.N. 2005. Plant pathology. 5 ed. San Diego, Estados Unidos. Academic Press. 905p.

2. ALLEN, R.; PEGG, K.; FORSBERG, L. 1980. Fungicidal control in pineapple and avocado of diseases caused by Phytophthora cinnamomi. Austral. J. Exp. Agric. Animal Husbandry. 20:119-124.

3. AVELING, T.; RIJKENBERG, F. 1986. Infection of susceptible avocado by Phytophthora cinnamomi. South Afr. Avocado Growers Assoc. Yearbook. 9:55-56.

4. BARTOLI, J.A. 2008. Manual técnico del cultivo de aguacate Hass (Persea americana L.). La Lima, HN, FHIA. Disponible desde Internet en: http://www.hondurasag.org (con acceso 27/10/2013).

5. BEKEY, R. 1987. California avocado diseases. California Grower. 11(5):18-21.

6. BERNAL, J.; BALLEN, M. 2007. Fosfitos en nutrición vegetal: 2a entrega, Calcio y fósforo en las plantas. ACOPAFLOR La Revista. p.38-42.

7. BROADBENT, P.; BAKER, K.F. 1974. Comportamiento de Phytophthora cinnamomi en suelo supresivo y favorable a la Pudrición de raíz. Diario Austral. Invest. Agr. 25:121-137.

8. CASTAÑO-ZAPATA, J. 1989. Estandarización de la estimación de daños causados por hongos, bacterias y nematodos en fríjol (Phaseolus vulgaris L.). Fitopat. Col. 13(1):9-19.

9. CASTAÑO-ZAPATA, J.; DEL RÍO, L.1994. Guía para diagnóstico y control de enfermedades en cultivos de importancia económica. $3^{\mathrm{a}}$ ed. Zamorano Academic Press. Honduras C.A. 287p.

10. CHAPMAN, D. 1973. Diagnostic criteria for plants and soils. Quality Printing Inc. Riverside, California. USA. p.13-23.

11. COFFEY, M.D. 1987. Phytophthora root rot of avocado. Plant Disease. 71(11):1046-1052.

12. COFFEY, M.D. 1991. Cause and diagnosis of avocado root rot. California Grower. 15(3):17-23.

13. DRENTH, A.G., WAGELS, B., SENDALL, C.O., DWYER, G.; INWIN, J.A. 2006. Development of a DNA-based method for detection and identification of Phyto- 
phthora species. Austral. Plant Pathol. Soc. 35: 147159.

14. DOWNER, J.; FABER, B.; MENGE, J. 2002. Factors affecting root rot control in mulched avocado orchards. HortTech. 12(4):601-605.

15. ERWIN, D.C.; RIBEIRO, O.K. 1996. Phytophthora diseases worldwide. APS Press, St. Paul. 562p.

16. FRAC. 2011. FRAC Code List: Fungicides sorted by mode of action (including FRAC Code numbering). Fungicide Resistance Action Committee. 10p.

17. GARCÍA, C.; GIL, F.; HERNÁNDEZ, T.; TRAZAR, C. 2003. Técnicas de análisis de parámetros bioquímicos en suelos: medida de actividades enzimáticas y biomasa microbiana. Ed. Mundi-Prensa. Madrid. 347p.

18. GARCÍA, A.; IBAÑEZ, J.J. 1994. Seasonal fluctuations and crop influence on microbiota an enzyme activity in fully developed soils of central Spain. Arid Soil Res. Rehab. 8:161-178.

19. GABOR, B.K.; COFFEY, M.D. 1990. Quantitative analysis of the resistance to Phytophthora cinnamomi in five avocado rootstocks under greenhouse conditions. Plant Disease. 74(11):882-885.

20. GUERRERO, R.R. 1995. Fertilización de cultivos en clima medio. Monómeros Colombo Venezolanos. S.A. $2^{a}$ Ed. 262p.

21. HO, H. 1992. Keys to the species of Phytophthora in Taiwan. Plant Pathol. Bull. (Taiwan). 1:104-109.

22. HO, H.; ANN, F.J.; CHANG, H.S. 1995. The genus Phytophthora in Taiwan. Institute of Botany. Acad. Sinica. Monograph series 15. 86p.

23. KELLAN, M.K.; COFFEY, M.D. 1985. Quantitative comparison of the resistance to Phytophthora root rot in three avocado rootstocks. Phytopath. 75:230-234.

24. LATORRE, B. 1988. Enfermedades de las plantas cultivadas. $2^{\mathrm{a}}$ ed. Santiago, Universidad Católica de Chile. $307 p$.

25. LEE, B.S.; ZENTMYER, G.A. 1982. Influence of calcium nitrate and ammonium sulfate on Phytophthora root rot of Persea indica. Phytopath. 72:1558-1564.

26. LITTLE, T.M.; HILLS, F.J. 1987. Métodos estadísticos para la investigación en la agricultura. Ed. TRILLAS. México. 268p.
27. MONDINO, P. 2008. Control químico de enfermedades de plantas, segunda parte. Grupos químicos. Disponible desde Internet en: http://www.pv.fagro.edu.uy/ fitopato/cursos/fitopato/Materiales/Teoricos200708/ Control_quimico_de_enfermedades_de_plantas_\%202a_\%20parte.pdf (con acceso 16/10/2013).

28. MORA, G.; TELIZ, D.; GARCÍA, R.; SALAZAR, S. 1987. Manejo integrado de la tristeza (Phytophthora cinnamomi) del aguacate (Persea americana). Cuarta Eval. Anual. Rev. Soc. Mex. Fitopat.16:74-81.

29. PANCHOLY, S.K.; RICE, E.L. 1973. Soil enzymes in relation to old field succession: Amylase, cellulase, invertase, dehydrogenase and urease. Soil Sci. Soc. Am. Proc. 37:47-50.

30. PEGG, K.G.; FORSBERG, L.; WHILEY, A.W. 1982. Avocado root rot. Queensland Agric. J. 108:162-168.

31. PEGG, K.G.; COATES, L.M.; KORSTEN, L.; HARDING, R.M. 2002. Foliar, fruit and soilborne diseases. In: Whiley, A.W.; Schaffer, B.; Wolstenholme, B.N. (eds.). Avocado: Botany, Production and Uses. CABI Publ. p.299-338.

32. PLM®. 2012. DEAQ. Diccionario de especialidades agroquímicas. Edición 22. 1.283p.

33. ROSAS, M.; TELIZ, D.; GARCÍA, R.; SALAZAR, S. 1986. Influencia de estiércol, alfalfa y metalaxil en la dinámica poblacional de Phytophthora cinnamomi Rands causante de la tristeza del aguacate (Persea americana Mill). Rev. Mex. Fitopat. 4:114-123.

34. SHEA, S.P.; BROADBENT, P. 1983. Development in cultural and biological control of Phytophthora diseases. In: Erwin, D.C.; Bartinicki-Garcia, S.; Tsao, P.H. (eds). Phytophthora: Its Biology, Taxonomy, Ecology and Pathology. APS Press. p.335-350.

35. SILVA, M.F. 1994. Fertilidad de suelos, diagnóstico y control. Soc. Col. de la Ciencia del Suelo. Nueva Ed. Santafé de Bogotá. 507p.

36. TAMAYO, P.J. 2008. Enfermedades y desordenes abióticos. En: Tecnología Para el Cultivo del Aguacate. Manual Técnico 5. CORPOICA. C.I. La Selva. Rionegro Antioquia. Colombia. 241p.

37. TSAO, P.; GUY, S. 1983. Factors affecting isolation and quantitation of Phytophthora from soil. In: Erwin, C.D.; Barnicki-Garcia, S.; Tsao, P.H. (eds). Phytophthora: Its Biology, Taxonomy, Ecology and Pathology. APS Press. p.219-235. 
38. VALENZUELA, J.G.; TELIZ, D.; GARCÍA, R.; SALAZAR, S. 1985. Manejo integrado de la tristeza (Phytophthora cinnamomi) del aguacatero en Atlixco, Pue. Rev. Mex. Fitopat. 3:18-30.

39. VIDALES, J.A.; ALCÁNTAR, J.J. 2006. Mal de la Tristeza (Phytophthora cinnamomi Rands) del aguaca- tero (Persea americana Mill.). Bol. El Aguacatero No. 45 Disponible desde Internet en: http://www. aproam.com/boletines/aguacatero.html (con acceso 16/10/2013).

Recibido: Octubre 4 de 2013

Aceptado: Marzo 28 de 2014

Como citar:

Leal, J.M.; Castaño, J.; Bolaños, M.M. 2014. Manejo de la pudrición radical (Phytophthora cinnamomi Rands) del aguacate (Persea americana Linneo). Rev. U.D.C.A Act. \& Div. Cient. 17(1): 105-114. 